\title{
Maternal death due to severe pulmonary oedema caused by falciparum malaria: a case report
}

\author{
I. Adam ${ }^{1}$ and M.I. Elbashir ${ }^{2}$
}

\section{Introduction}

Pregnancy increases susceptibility to falciparum malaria, and the level of disease transmission in an area influences the manifestations of the disease during pregnancy. In areas of low and unstable transmission, malaria during pregnancy is usually symptomatic, unlike the situation in areas of high endemicity, where patients are usually asymptomatic or present with severe anaemia $[1,2]$. There is some degree of immune suppression during pregnancy, with sequestration of infected red blood cells in the placenta through binding to chondroitin sulfate $[3,4]$.

Malaria constitutes $40 \%$ of the infectious disease burden and approximately $50 \%-70 \%$ of all outpatient visits to hospitals in Sudan [5]. In eastern Sudan, malaria is mesoendemic and the predominant malaria species is Plasmodium falciparum $[6,7]$. We have previously observed different forms of clinical presentations of severe malaria among pregnant Sudanese women, including cerebral malaria, and that all parities were infected [8]. Antimalarial drug resistance is also a growing threat in Sudan [6].

We report a young pregnant woman with severe chloroquine-resistant falci- parum malaria and pulmonary oedema who died of respiratory failure in spite of adequate treatment with quinine in hospital.

\section{Case report}

A 24-year-old primigravida presented to New Halfa Teaching Hospital (eastern Sudan) on 28 December 2002 with amenorrhoea for 34 weeks, fever, headache, productive cough and vomiting for 5 days. Two days before admission she had received 5 injections of chloroquine after confirmation of $P$. falciparum infection without improvement.

The following findings were recorded on presentation: weight $73 \mathrm{~kg}$, temperature $39.2^{\circ} \mathrm{C}$, pulse 95 beats/minute, blood pressure $110 / 70 \mathrm{mmHg}$, respiratory rate 30 breaths/minute, haemoglobin $9 \mathrm{~g} / \mathrm{dL}$, total white blood cells 8500 cells $/ \mu \mathrm{L}$, blood glucose $110 \mathrm{mg} / \mathrm{dL}$, blood urea $25 \mathrm{mg} / \mathrm{dL}$, serum creatinine $0.9 \mathrm{mg} / \mathrm{dL}$. Her chest was clear clinically, with no crepitations or rhonchi. Examination of the baby showed a fundal height that correlated with the mother's dates, cephalic presentation and audible heartbeat.

The diagnosis of chloroquine-resistant falciparum malaria with or without chest

${ }^{1}$ New Halfa Teaching Hospital, New Halfa, Sudan.

${ }^{2}$ Faculty of Medicine, University of Khartoum, Khartoum, Sudan.

Received: 12/10/03; accepted: 23/12/03

بلملة الصحية لشرق المتو سط، منظمة الصحة العلمية، البحلد العاشر، العددان ع-ه، ع • • 
infection was suspected initially. Thick blood films confirmed parasitaemia and the patient was put on quinine hydrochloride infusion in 5\% dextrose $600 \mathrm{mg} 3$ times daily and also given benzyl penicillin 1 million IU intravenously every 4 hours.

After 24 hours the woman's axillary temperature was slightly lower at $38.8^{\circ} \mathrm{C}$, respiratory rate had risen to 50 breaths/ minute and the blood film was still positive, but she was cyanosed. Pulmonary oedema was suspected and the diagnosis was confirmed by chest X-ray. The patient was put on intermittent oxygen, furosemide $40 \mathrm{mg} /$ $\mathrm{kg}$ twice daily and $15 \mathrm{mg}$ of morphine was given intramuscularly. Quinine and penicillin were continued but there was no improvement.

On the third day the patient's blood films were negative but she was deeply cyanosed, respiratory rate was 54 breaths/ minute, temperature was $38.4{ }^{\circ} \mathrm{C}$ and she had chest crepitations. She died on the third day from respiratory failure.

\section{Discussion}

This report draws the attention to the threat caused by falciparum malaria in pregnant women in areas of low and unstable malaria transmission such as that in eastern Sudan. However, complications of falciparum malaria in adults, especially lung injury and renal failure, can occur after several days of treatment when the parasites have de- creased from baseline or even when parasites disappear from the peripheral blood [9]. This patient presented with manifestations of malaria after 5 days of treatment with chloroquine, a drug that is showing increasingly high failure rates in Sudan [6].

In many Asian and African countries, malaria is reported as one of the main causes of maternal mortality [10-14], and in central Sudan it was the leading cause of maternal mortality over the 15 years 1985 99, accounting for $37 \%$ of maternal deaths [12]. Therefore, the utmost care and prompt early treatment with effective drugs is recommended in pregnant women, due to high susceptibility to severe complications in areas of low and unstable transmission, and the rising rate of multi-drug resistance in all malaria-endemic areas. The World Health Organization recommends quinine as the drug of choice for severe falciparum malaria [15]. However, it should not be relied upon as the sole treatment, but attention should be also directed to good monitoring of blood $\mathrm{pH}$ and gases (services lacking in our centre) and of venous pressure to avoid over-hydration that may cause or exacerbate pulmonary oedema. Likewise, intensive care units with a ventilator are of paramount importance for patients with pulmonary oedema. As in over-hydration, heart failure, renal failure and pulmonary irritants, falciparum malaria should be remembered as a cause of pulmonary oedema.

\section{References}

1. Brabin BJ et al. A study of the consequences of malaria infection in pregnant women and their infants. Parassitologia, 1993, 35(suppl.):9-11.

2. Nosten F et al. Malaria during pregnancy in an area of unstable endemicity. Transactions of the Royal Society of Tropical Medicine and Hygiene, 1991, 85:424-9.
3. Fievet $\mathrm{N}$ et al. Immune response to Plasmodium falciparum antigens in Cameroonian primigravidae: evolution after delivery and during second pregnancy. Clinical experimental immunology, 1997, 107:462-7.

4. Fried M, Duffy PE. Adherence of plasmodium falciparum to chondroitin sulfate $A$

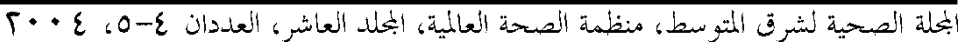


in human placenta. Science, 1996, 272: 1502-4.

5. El Gaddal AA. The experience of the Blue Nile Health Project in the control of malaria and other water associated diseases. In: American Association for Advancement of Science. Malaria and development in Africa. A cross-sectoral approach. Washington DC, AAAS, 1991.

6. Adam I et al. In the Sudan: chloroquine resistance is worsening and quinine resistance is emerging. Sudan medical journal, 2001, 39:5-11.

7. El Gadal AA. Malaria in the Sudan. In: Buck AA, ed. Proceedings of the conference on malaria in Africa. Washington, DC, American Institute of Biological Sciences/USAID, 1986:156-9.

8. Adam I et al. Quinine therapy in severe Plasmodium falciparum malaria during pregnancy in Sudan. Eastern Mediterranean health journal, 2004, 10(1/2):15966.

9. World Health Organization, Communicable Diseases Cluster. Severe falciparum malaria. Transactions of the Royal Society of Tropical Medicine and Hygiene, 2000, 94(suppl. 1):S1-90.
10. Wickramasuriya GAW. Malaria and ankylostomiasis in the pregnant woman. Their more serious complications and sequelae. Oxford, Oxford University Press, 1937.

11. Menon R. Pregnancy and malaria. Medical journal of Malaysia, 1972, 27:115-9.

12. Dafallah SE, El Agib FH, Bushra GO. Maternal mortality in a teaching hospital in Sudan. Saudi medical journal, 2003, 24:369-73.

13. Fawcus $S$ et al. Community based study cause of maternal mortality in rural and urban Zimbabwe. Central African journal of medicine, 1995, 41:105-13.

14. Urassa $E$ et al. Female mortality in the reproductive ages in Dar es Salam, Tanzania. East African medical journal, 1994, 71:226-31.

15. World Health Organization, Division of Control of Tropical Diseases. Severe and complicated malaria. Transactions of the Royal Society of Tropical Medicine and Hygiene, 1990, 84(suppl. 2):1-65.

لبحلة الصحية لشرق المثتو سط، منظمة الصحة العالمية، المجلد العاشر، العددان ع-0، ع • • 